\title{
ROTARY FRICTION WELDING AND DISSIMILAR METAL JOINING OF ALUMINIUM AND STAINLESS STEEL ALLOYS
}

\author{
S. Senthil Murugan*, P. Sathiya², A. Noorul Haq ${ }^{2}$ \\ ${ }^{1}$ Rajalakshmi Engineering College, Chennai - 602 105, Tamilnadu, India \\ ${ }^{2}$ National Institute of Technology, Tiruchirappalli - 620015 , Tamilnadu, India \\ *Corresponding author’s email address: gctsegan@gmail.com
}

\begin{abstract}
Friction welding (FW) is cost-effective, efficient, occupational safer and also ecofriendly in the absence of pollution, smoke, fume, and IR radiation during welding than conventional welding technologies. In this paper, the joining of aluminium AA6063 and steel SS304 dissimilar metal is explained with different faying surfaces and their SEM images of weld interface (WI), joint quality, tensile and yield strength, and the axial shortening are evaluated and compared. The joint quality factor of the experiment faying surface modification 'E3' was the maximum and about $>100 \%$ with $236 \mathrm{MPa}$ strength. The axial shortening was also less than 27 $\mathrm{mm}$. The joint with hemispherical faying surface showed ' $U$ ' shaped WI and the joint with taper faying surface showed ' $V$ ' shape WI. So, the cross-sectional area of WI can be increased and the strength also increased. $F W$ yields very high strength, lowstress weld with no weld defects such as porosity, voids etc. Here, in most cases, the joint strength is equal to base metal strength and it can avoid fastening to join two metals. FW has a minimal and narrow heat-affected zone (HAZ) of few microns size that differentiates $F W$ from other welding techniques. The grain size of HAZ is directly proportional to the heat input during welding. During fusion welding of dissimilar materials, a lot of intermetallic compounds are formed at the weld interface and that will lead to poor strength of the welding because they have different chemical and mechanical qualities; therefore $F W$ is a good choice for joining dissimilar metal rods as the intermetallic compounds can be reduced by $F W$.
\end{abstract}

KEYWORDS: friction welding, faying surface, dissimilar joining, aluminium, steels.

\section{INTRODUCTION}

Welding is a process to join two parts permanently by the application of pressure and (or) heat. The welding processes can be classified based on whether the weld base metal is melting or not. The type of welding process in which the faying surfaces of base metal melt down by the application of heat is known as fusion/conventional welding. If the pressure is applied instead of applying the heat, then it is called solid-state welding. However, in this process heat may produce internally without melting the base materials. Friction Welding, Pressure Welding, Friction Stir Welding, Forge Welding, Cold Welding, Diffusion Welding, Explosive Welding, and Ultrasonic Welding are solid-state welding. Resistance Welding, Gas Welding, Arc Welding, Plasma Arc Welding, Laser Beam Welding, Electron Beam Welding, Gas Metal Arc welding, and Gas Tungsten Arc Welding are fusion welding. Utilization of advanced welding techniques to join dissimilar metals is needed as the conventional welding processes are ineffective. In conventional welding, materials are prone to participating in the reaction at elevated welding temperatures [1].

The conventional problems related to the welding of dissimilar joints can be overcome by the solid-state welding process [2]. Since the melting is not reached, solid-state welding processes will not produce the welding defects as in fusion welding [3].

As the different chemical compositions and materials properties, joining of stainless steel with aluminium is difficult by fusion welding processes; both can be successfully welded by the Friction welding process, which is a solid-state non-fusion joining method. The significance of $\mathrm{FW}$ is the bonding temperature that is lesser than the melting temperature of the base metals and the suitability for high production in industries. Solid-state welding especially friction welding is popular in the production industries as a consequence of the benefits such as a reduction in material wastage, less 
production time, easy management of welding parameters, high production rate, low power consumption for joining, eco-friendly method, well reproducibility and excellent work performance $[4,5]$. During FW, temperature and stress developed are governing welding parameters, so a piece of knowledge is needed to identify the optimum parameters thus improving the design of joining dissimilar metals.

This paper aims to explain the fundamental concepts behind the FW process with its applications, significance, safety and characteristics. Further, this paper includes the challenges that are to be faced during the $\mathrm{FW}$ of aluminium and steel and reveal the results of experiments done in the joining of AA6063 and SS304 steel rods.

Friction welding fabricates admirable quality weld joints between dissimilar or similar metals [6] by generating heat through mechanical friction as in Figure $1 \mathrm{~b}$ between both workpieces in relative motion to one another with a lateral force called an upset force to plastically displace and fuse the base materials (Fig. 1c) in faying surfaces. Friction pressure (FP) is responsible for the joining at the seconds called friction time (FT), the upset pressure (UP) is applied when the friction pressure is over to increase the bonding. This is one of the highly recommended processes for joining cylindrical dissimilar materials [7].

The principle of the RFW consists of three main steps (Fig. 1a-1d [8]), namely 1) part rotation (Fig. 1a), 2) friction generation and friction weld (Fig. 1b), 3) application of upset pressure (Fig. 1c). Upset pressure (UP) is for the consolidation of the weld and figure $1 \mathrm{~d}$ is the completed weld. Rotary and linear are the two major types of FW. In the rotary friction welding (RFW) machine one part rotates as in figure 1e instead of sliding as in linear friction welding (LFW). Various RFW processes are there such as inertia, direct-drive and hybrid friction welding. Each technique has the exclusive advantages relying on the materials to be welded and the geometries and the shape of the weld specimens etc.

The entire smooth surface contains microscopic projections. These are known as asperities and are responsible for generating friction between surfaces by having the interaction among these asperities when one slides over another surface. The heat produced in the FW process is mainly due to the asperity through plastic and elastic yielding and the mechanical movement between welding specimens, which causes the specimens to soften state and become viscous. At this stage, the materials are to be bonded by mechanical motion. This phenomenon is normally followed in FW for joining similar/dissimilar metals.

In RFW, among the two rods, one of them in the chuck and the other in a pneumatic or hydraulic operated ram, the axial load (mechanical energy) by the reciprocating ram and the rotary motion by the chuck rotation generates frictional heat (thermal energy) between two rods to weld both of them together. Finally, an additional pressure (upset pressure-UP) is applied for a few seconds on the weld joint when friction is stopped to complete the weld.

a)

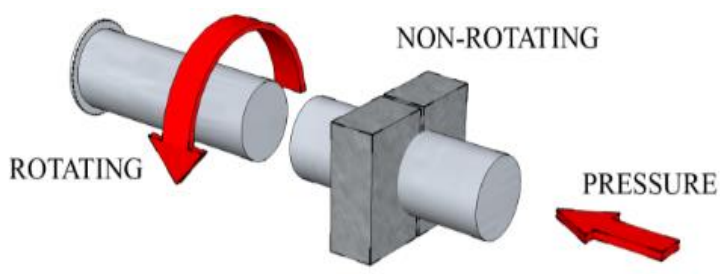

b)

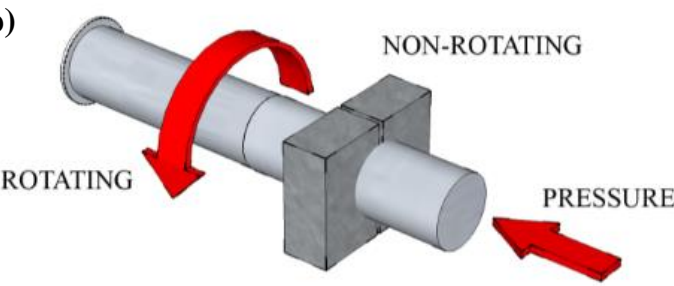

c)

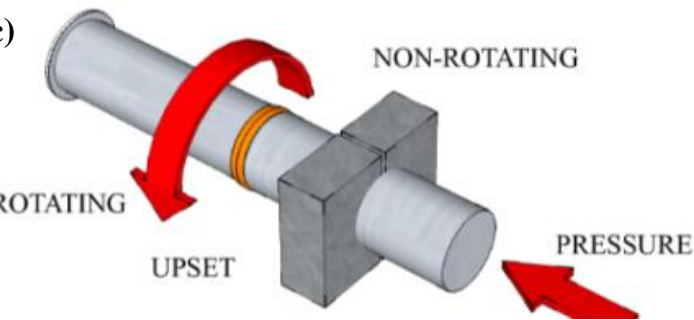

d)
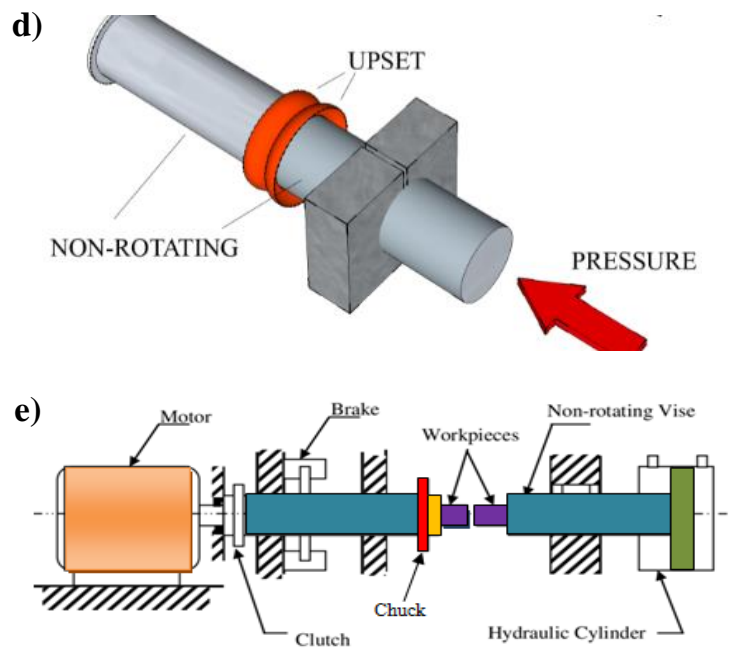

Fig. 1. Friction welding: a-d) concept in stepwise [8]; e) Schematic diagram of friction welding machine set up [9]

Friction welding means the generation of heat required for joining by the interaction between two faying surfaces of the metals during rotation in the friction welding machine. The intermolecular diffusion developed between the two faying faces of weld specimens performs the welding. Here the interface temperature is lower than the melting temperature of base metals so melting will not occur in FW. In FW, the coalescence is obtained by the 
synergic effect of pressure and the relative motion between the parts to be welded.

The schematic diagram of the direct-drive type friction welding (DDFW) process was given in figure 1e. Here, DDFW was used for the experiments. In DDFW, unlike a hollow pipe, a solid bar will not have any relative motion at the centre of the part. To generate sufficient centre heating, one has to increase the energy storage and the load to dissipate the high energy more quickly, depending on the conductive heating from the outside of the part inward. That would be better for the proper amount of heat required at the centre of the parts. Regrettably, the increased energy and increased load have a cost and safety associated with it. In lieu, DDFW continually adds energy using an electric motor, which in turn, drives the rotating component at a speed in rpm. If the parts are to rotate longer then more energy will be added to the weld. This additional energy will convert into heat, which will soak into the centre of the part. The direct drive process accomplishes the same increase in energy through added cycle time instead of increased energy storage, allowing the parts to receive enough heat in the centre of the parts to make a quality weld. Since the melting is not reached, this welding process will not produce the welding defects as in fusion welding.

Figure 2 show the relationship of the different friction welding phases with time. According to the figure, three phases are there (i.e.) friction phase, forging phase, braking phase. During the friction phase, the speed and the friction force are constant. At the same time, speed is suddenly reduced to zero conversely friction force; torque and upset force suddenly increase during the braking phase. While in the forging phase the forging force and upset force maintain constant. The level of upset force during the forging phase and the upset level during the start of the friction phase are known as upset length. The completion of the weld takes place during the forging phase.

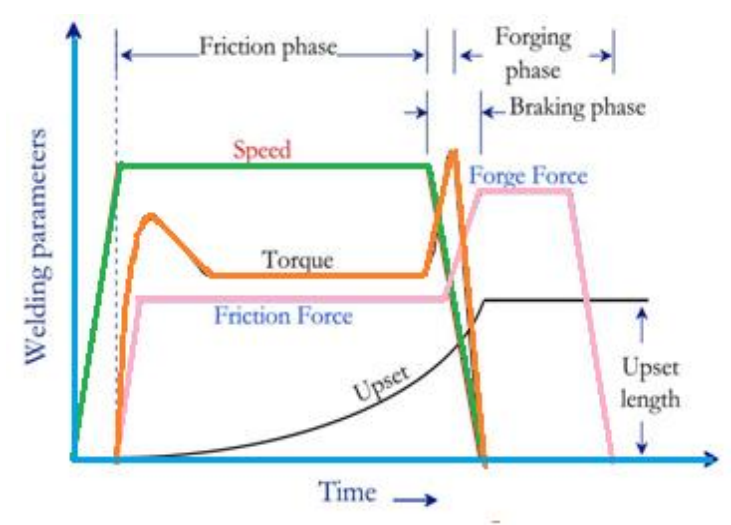

Fig. 2. Friction welding process parameters with time [10], [11], [12]

In friction crush welding (FCW), the results are material dependents and aluminium alloy joint reaches bond strength of $90 \%$ of its base metal strength and this process can produce high-quality welds. Inertia friction welding (IFW) can also be used instead of RFW as the drive required is small for similar specimen dimensions. IFW is also a proven weld technique with a regression model to test the influence of parameters [13]. Welding becomes risky and unhealthy unless the right precautions and safety measures are followed. The welding hazards may threaten the welders and deteriorate their physical natures and their life. It is recognized that fumes, electric shock, heat, light \& radiation, ergonomics \& noise are the five major hazards in most welding processes.

The study finds the hazards behind the friction welding process; they are noises, which are from the motor, rotation of chuck (danger zone), high friction and upset pressures and the axial movement of the hydraulic ram during welding, and the risk of operator's hand caught between the male (hydraulic axially moving system) and female (chuck) adaptors in the rotary friction welding machine and vibrations.

Table 1. Welding hazards* observed related to FW

\begin{tabular}{|c|c|c|c|c|c|c|c|c|}
\hline Noise & $\begin{array}{c}\text { Heat, } \\
\text { fire, } \\
\text { burns }\end{array}$ & $\begin{array}{c}\text { UV } \\
\text { radiation }\end{array}$ & $\begin{array}{c}\text { Electric } \\
\text { shock }\end{array}$ & Ergonomics & $\begin{array}{c}\text { Toxic } \\
\text { fumes } \\
\text { and gases }\end{array}$ & Vibration & $\begin{array}{c}\text { Bright } \\
\text { light }\end{array}$ & $\begin{array}{c}\text { Explosive } \\
\text { gases }\end{array}$ \\
\hline$\checkmark$ & $\mathrm{x}$ & $\mathrm{x}$ & $\checkmark$ & $\checkmark$ & $\mathrm{x}$ & $\checkmark$ & $\mathrm{x}$ & $\mathrm{x}$ \\
\hline
\end{tabular}

*' $\checkmark$ '- hazard present, $\mathrm{x}$ - no hazard

The hazards are discussed in table 1. Though FW is eco-friendly, it is recommended to have good machine guarding systems and sound control enclosures around the FW machine. It takes a safety precaution like a machine shop; the machine operator must not have loose hair, and cloth, Jewels on their hands and necks. A fixed gate on the rear side and a transparent sliding door in front are needed for the FW machine- An interlocking is suggested to protect the machine operators. It further requires a sensing system to sense the physical movements and then to end the machine.

\section{MATERIALS AND METHODS}

Here, the dissimilar alloys AA6063.aluminium and SS304 alloy are to be joined. Joining of dissimilar alloys is demanded industrial applications and is effectively possible with the FW process, which is a solid-state joining process as it does not cause melting of the base metal because the welding temperature is 
lesser than the melting temperature of the base metals [14]. So, it is well-liked among the welding techniques for joining dissimilar metals. For the instance, friction welding allows for the joining of dissimilar materials such as steel to stainless steel, aluminium to steel or copper, stainless to nickel-base alloys, and a host of other combinations using various materials that are not weldable through traditional methods. Welding of dissimilar metals by fusion welding process is a tough task, as both metals have different thermomechanical properties and chemical compositions. Samaresh Mohammadzadesh Polami et al. [15] emphasized the application of friction welding in joining bimetallic parts and the importance of dissimilar joints in reducing the fuel cost in heavyduty trucks. Design engineers are increasingly faced with the need to join dissimilar materials as they are seeking creative new structures or parts with tailorengineered properties. Applications of the friction welding processes and dissimilar joints are inevitable in many industries as different properties are necessary with accurate applications [16]. For instance, friction welding proved as a technology for fabricating titanium alloy bladed disks in aero engines and aircraft structural components [17].

Dissimilar metals are welded together to maximize the benefits that each metal produces while minimizing the drawbacks. The combination of corrosion resistance, mechanical properties, and electrical properties of two or more materials are the main reasons for the dissimilar welding in industry. For instance, Steel is a strong, cheap and easy-towork-with metal, so it is often the go-to choice for many industries like the automotive sector. Aluminium, on the other hand, is not as cheap or as strong and is more complicated to work with, but is much lighter than steel. Alongside this, it is resistant to corrosion and rust. So, a combination of these two metals is a great way to maximize these benefits. Lightweight structures with high strength to weight ratio are appreciated for transport vehicles.

However, the development of such structures could not be possible without the innovations in welding techniques and dissimilar metal joints. So a state-of-the-art technology is needed to joint dissimilar joints with good joining properties. Though FW is a promising technique and one of the pressure welding techniques to joint dissimilar metals due to its high efficiency with a narrow HAZ, the research on joining of austenitic stainless steel (at different carbon content) with $\mathrm{Al}-\mathrm{Si}-\mathrm{Mg}$ alloys by rotary friction welding is limited. From literature, it is observed that to face the difficulty while welding of dissimilar metals that are with different coefficients of thermal expansion. The dissimilar metal welds are widely used in boiler, oil refining industries.

In the manufacturing industries, similar joints have often been substituted with dissimilar joints that may have a comparatively high strength-to-weight ratio. However, the welding of such dissimilar joints requires sophisticated processes and must be done under high scrutiny. Welding of ferrous metal with non-ferrous metal is quite challenging due to the varied physical and chemical properties of the metals [18]. As demand for joining dissimilar materials rods fo7 industrial applications, continuous or direct drive friction welding (DDFW) application is remarkable. DDFW or continuous drive friction welding is a kind of rotary welding and one of the friction welding processes. The dissimilar weld of high strength steel and aluminium alloy is having significant application in fuel-efficient vehicle body manufacturing [19]. It is mandatory to stop the melting of base metals since the joining metals have different melting points and thermal conductivities while welding dissimilar metals. So demand is there to join the dissimilar metals without melting them; in this situation, DDFW plays a crucial role in joining.

The different experimental methods were tried to join both SS304 and AA6063 alloy using the DDFW type friction welding process as per the procedure shown in figure 1e. Figure 3 shows the experimental methods E1, E2 and E3. The alloy SS304 stainless steel (SS) was kept at the chuck on the left side of the machine.

The experiments were done as per parameters shown in table 2 . The specimen size was $100 \mathrm{~mm}$ in length and $12 \mathrm{~mm}$ in diameter. The novelty of the work is to introduce the new faying surfaces and develop dissimilar joints with them.

Table 2. FW experimental parameters

\begin{tabular}{|c|c|c|c|c|c|}
\hline $\begin{array}{c}\text { Upset pressure } \\
\text { (UP) }\end{array}$ & $\begin{array}{c}\text { Friction } \\
\text { pressure (FP) }\end{array}$ & $\begin{array}{c}\text { Friction } \\
\text { Time (FT) }\end{array}$ & Upset time & Chuck rotation & $\begin{array}{c}\text { Axial } \\
\text { movement }\end{array}$ \\
\hline $2.4 \mathrm{MPa}$ & $1.8 \mathrm{MPa}$ & $5 \mathrm{~s}$ & $3 \mathrm{~s}$ & $1300 \mathrm{rpm}$ & $3 \mathrm{~mm} / \mathrm{s}$ \\
\hline
\end{tabular}

\section{RESULTS AND DISCUSSION}

After the experiments, the fabricated dissimilar friction weld that consists of AA6063 and AISI304 of the E1 experiment is shown in figure $4 \mathrm{a}$ and their strengths were analysed. The penetration of steel 304 was into the aluminium specimen 6063 as it is soft.
The initial length of both weld specimens was 200 $\mathrm{mm}$ and the final length of the prepared joint was about $175 \mathrm{~mm}$. The metal loss of about $25 \mathrm{~mm}$ was due to the penetration of SS304 alloy into AA6063 alloy during $\mathrm{FW}$. This phenomenon is known as "Axial shortening". Figure $4 \mathrm{~b}$ shows the axial shortening of experiments E1-E3. The aluminium 
metal came out like a flash in the centre of the joint as the frictional effect soften the soft metal aluminium (melting point is $660^{\circ} \mathrm{C}$ ).
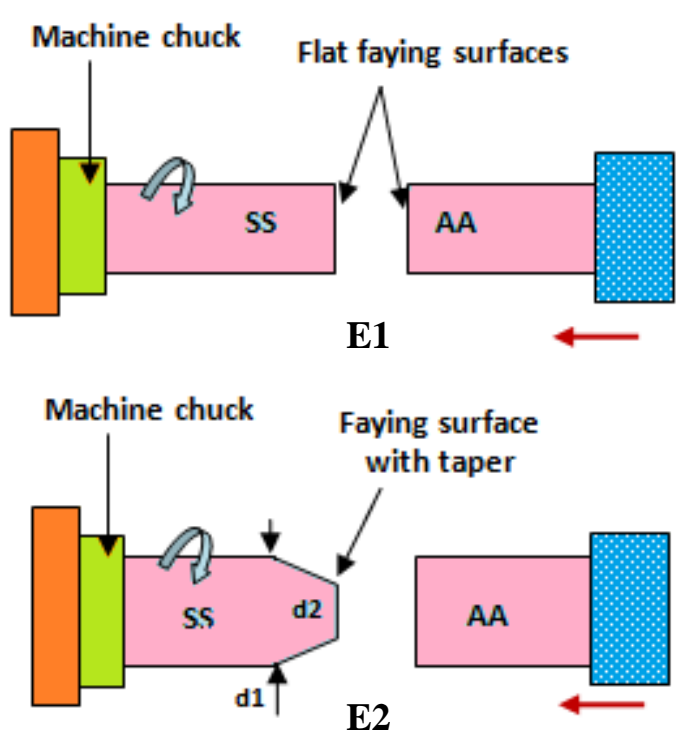

Machine chuck

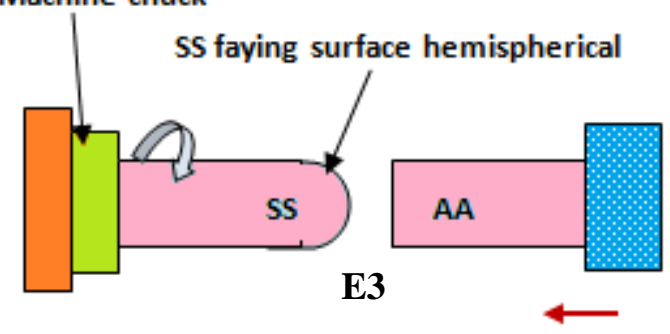

Fig. 3. Experimental methods E1, E2, E3; where d1 $=\phi$ $12 \mathrm{~mm}, \mathrm{~d} 2=\phi 6 \mathrm{~mm}, \mathrm{SS}-\mathrm{AISI} 304$, AA-AA6063

The SEM images of the weld joints made were shown in figures $4 \mathrm{c}-\mathrm{e}$ for the experiments E1-E3 respectively.

The bonding and the coalescence between the two dissimilar alloys were good due to the frictional joining effect. Some micropores were found in the weld interface shown in figure $4 \mathrm{c}$. From figure $4 \mathrm{c}$, the weld interface is as a straight line, while from the figures $4 \mathrm{~d}$ and e the weld interfaces of joints by the experiments E2 and E3 it was observed that the different faying surfaces on the SS304 side, show in figure 3, created the " $\mathrm{V}$ ' shaped WI [20] and Curved interfaces respectively. These different interfaces increased the tensile strength because of the increase of interface contact area. The thickness of the interface was increased with the increase of FP.

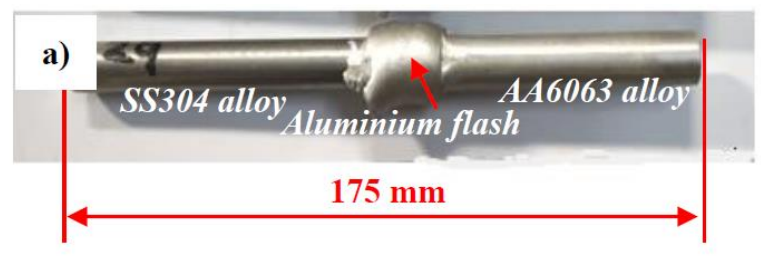

b) $\quad$ Axial shortening (mm)
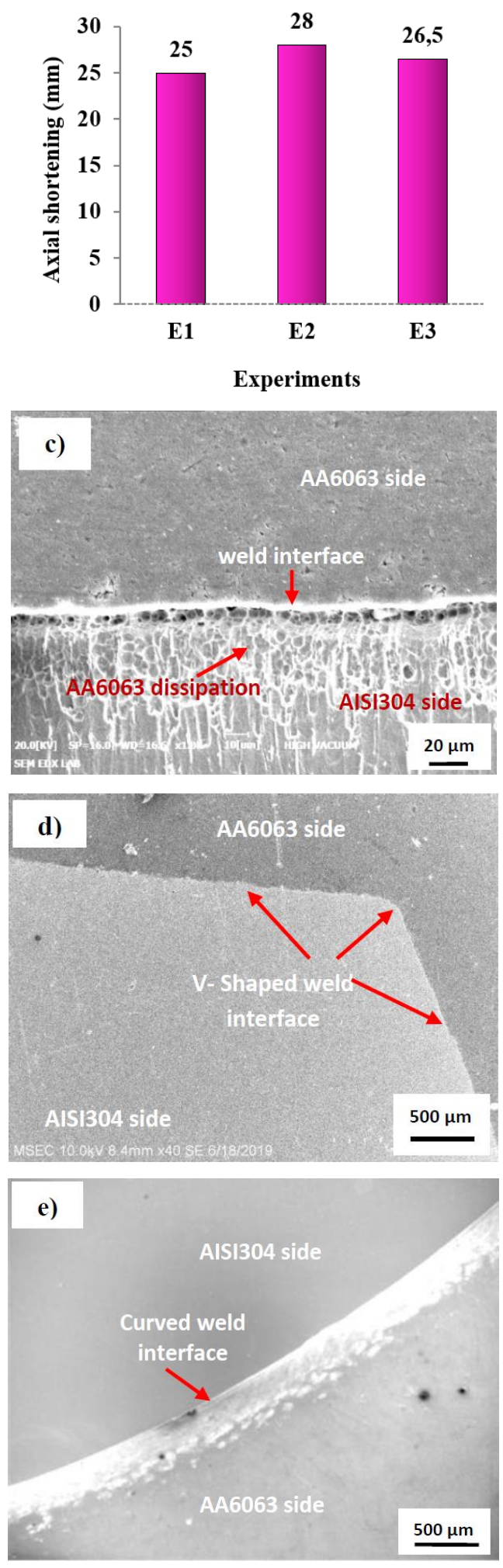

Fig. 4. Welded joint: a) dissimilar weld joint, b) axial shortening, c-e) SEM images of weld interfaces of experiments E1 to E3

The fabricated different dissimilar weldments were tested and their axial shortening, joint efficiency/quality factor, tensile and yield strength 
were evaluated. For the tensile testing ASTM E8 standard was followed. Figures $5 \mathrm{a}$ and $\mathrm{b}$ show the joint quality factor of the joints and the tensile property of the weld joints respectively. The joint quality factor estimation is keen on achieving suitable weldments for the applications. It means that the weld strength decides the value of the quality factor and depends on the tensile property of the joint. In this work, the joint quality factor was calculated as per equation no 1 . The tensile strength of soft base aluminium 6063 alloys is considered as $215 \mathrm{MPa}$. The estimated values are shown in figure $5 \mathrm{~b}$.

Joint quality factor $=\mathrm{T} 1 / \mathrm{T} 2$ (or)

(Joint efficiency)

where ' $\mathrm{T} 1$ ' is the tensile strength of the weld joint and ' $\mathrm{T} 2$ ' is the tensile strength of the soft base metal.
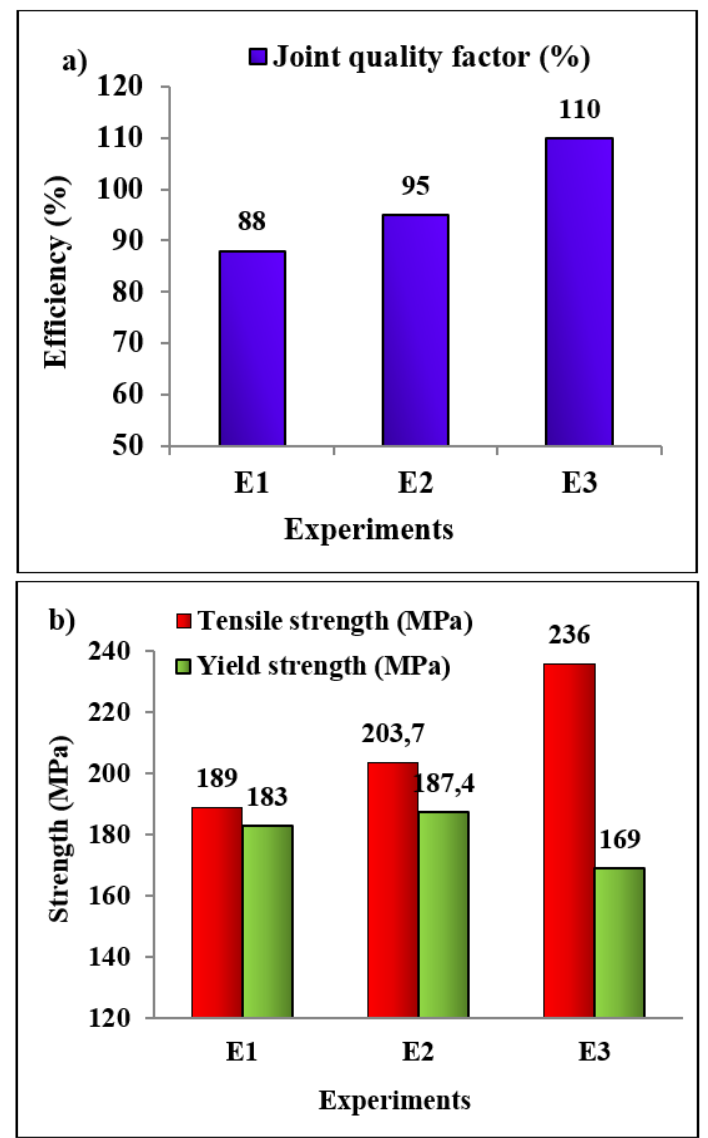

Fig. 5. Dissimilar joints proprieties: a) joint quality factor; b) tensile property of the dissimilar joints

All the FW experiments showed good weldments based on their bonding mechanism with a high joint quality factor or joint efficiency especially the experiments E3 and E2. The faying surface's geometrical modifications increased the joint quality factors by greater than $100 \%$. Similarly, from the results, the experiment (E3) with hemispherical bowl faying surfaces had the maximum strength up to 236 $\mathrm{MPa}$ as shown in figure $5 \mathrm{~b}$, while there was much difference between tensile and yield strength for E3. The strength of experiment E2 was also appreciable and the yield strength was a little bit higher than that of experiment E3. The information about the relationship between tensile (TS) and yield (YS) strength of the joint is given in table 3. From which, the E3 experiment has a low YS/TS ratio and TS and YS difference.

Table 3. Relations of the tensile and yield strength of the joints

\begin{tabular}{|c|c|c|c|}
\hline $\begin{array}{c}\text { Sl. } \\
\text { no. }\end{array}$ & Experiment & YS/TS ratio & $\begin{array}{c}\text { TS YS } \\
{[\text { MPa] }}\end{array}$ \\
\hline 1 & E1 & 0.968 & 6 \\
2 & E2 & 0.919 & 16.3 \\
3 & E3 & 0.716 & 67 \\
\hline
\end{tabular}

The friction welding process is eco-friendly and makes a clean work environment. It makes good joints with low distortion and high finish [21]. It improves productivity in industries and is suitable for bimetal joints. It is economical with stable quality and the surface finish of a weld joint is good and is suitable for both cylindrical and plate specimens. It yields high strength, low-stress weld with no porosity, and, in most cases, eliminates the need for costly premachining. The joint efficiency is efficient \& can avoid fastening and the contact area is huge in welding metals. It has a very small heat-affected zone and the formation of intermetallics can be reduced. It is also a labour saving operation and suitable for mass production. As the welding takes place in a solid-state manner, the defects like pores, solidification cracks can be avoided. It has low distortion on the welded parts. It does not require components needed in arc and gas welding processes like flux, filler rod, and shielding gas. There is no specimen edge preparation for the FW. Considering the productivity needed in industries, the FW process can be easily automated and its parameters can be controlled. The properties of joints produced by $\mathrm{FW}$ are superior to that of conventional processes. The machining required after the welding is also less for the joints prepared by FW so that the machining time and cost can be reduced. It is an environmentally clean process as it will not produce fumes and smoke. Dissimilar materials that cannot be welded by the conventional process can be welded with this process.

FW is sometimes limited to joining the contour and irregularly shaped specimens. A rigid clamping is needed for holding the big-sized weld specimens. Sometimes a heavy force is required for the joining. The improper welding parameter may damage the workpiece. A special precaution is needed from the safety point of view even though FW is eco-friendly welding. The friction welding process is popular in automotive, defence and aerospace industries like DRDO, Boeing, ISRO, HAL, NASA etc. RFW has many applications in the defence, marine, automotive 
and aerospace industries. Specifically, in aerospace industries, it is used to join aluminium, stainless steel, nickel and titanium. Further, it can be used for manufacturing heat pipe, piston for aircraft pump; aircraft hook bolts, and stator vane adjuster lever, and automotive parts including steel truck axels and casings, gear assembly, tubular transition joints combining dissimilar metals like aluminium-titanium, aluminium-stainless steel, and steel-aluminium for car body applications [22], cutting tools, turbine shafts, monel-to-steel marine fittings, copper-aluminium electrical connections. It is further helpful to join bar to bar, plate to plate (linear friction welding), tube to tube, tube to a plate, bar to a plate.

The properties of both steel and aluminium are not the same including the density of the metal. Steel is much higher than aluminium in weight and density. According to the strict rules on greenhouse emission and environmental protection, the transport industries are forced to reduce the weight of the vehicle. To aid the emission reduction, vehicle weight reduction is needed. So, it is better to replace the steel structure with strong aluminium alloys, but sometimes it is not possible to entirely replace the steel. So the joining between aluminium and steel is needed in industries. Aluminium, which is a lightweight metal, can be possibly joined to steel using the techniques like adhesion, brazing, and fastening. For superior structural applications, welding between aluminium and steel is required.

However, it is difficult to join dissimilar metals as both metals have different elements compositions and properties. Since the melting temperature of aluminium is almost half and more of steel, both metals should not completely soluble with each other. It is important to note down that in the molten stage during welding, the reaction between the metals forms brittle intermetallic compounds. So, this kind of intermetallic phase would show the brittle nature of the welded joints and inappropriate properties for industrial applications. When aluminium and steel is welded by fusion welding, the solubility of iron content in aluminium is low and about 0.04 wt. $\%$ over $350^{\circ} \mathrm{C}$ temperature which in turn tends to have the precipitation of $\mathrm{Fe}-\mathrm{Al}$. intermetallic compounds begin. The formation of intermetallic depends on diffusion, time, the temperature at the $\mathrm{Fe}, \mathrm{Al}$ interface. There is the possibility to have the hard $\mathrm{Fe}-\mathrm{Al}$ intermetallics like $\mathrm{FeAl}_{3}, \mathrm{Fe}_{3} \mathrm{Al}(892 \mathrm{Hv}), \mathrm{FeAl}(471 \mathrm{Hv}), \mathrm{Fe}_{2} \mathrm{Al}_{5}$ (1012 $\mathrm{Hv}), \mathrm{FeAl}_{2}(1060 \mathrm{Hv})$ at the interface. These are identified as harder, brittle with close to zero ductility, and reduced fracture toughness.

The thickness of phases should be thin as it influences the mechanical property. In arc welding, this kind of brittle intermetallic formation can be stopped by the aluminium coating on steel and bimetallic transition. The main aim of avoiding intermetallic is to maintain welding temperature as low as possible and minimize the contact time of faying surfaces at high temperatures. In friction welding, the friction plasticizes the faying surfaces and then the axial force induces the joining mechanism by displacing the plasticized materials from the interface.

Since friction welding prevents the long exposure time and retains weld metals at low temperatures without a liquid state, it reduces the formation of intermetallics. For example, it is difficult to join both austenitic stainless steel 304L and aluminium 6063 dissimilar metals (ferrous \& non-ferrous) with conventional fusion welding techniques as they have different compositions and properties, and they form the brittle intermetallic compounds at the weld interface at high temperature. Thus, welding of such dissimilar alloys is the challenging one to get maximum joint efficiency. Friction welding is good for joining ferrous and non-ferrous metals like aluminium and steel. By optimizing the FW parameters, and different processing routes we can increase the joint efficiency. Intermetallics formation can be one of the reasons for the failure or strength reduction in welded joints. Intermetallic is a solid phase having two or more metallic elements at stoichiometric proportion, for example, FeAl (iron aluminide). The aluminium rich $\mathrm{FeAl}$ intermetallics are with low density, lower strength and hardness than Fe rich intermetallics [23]. The strength and hardness of intermetallics can be increased by grain refinement. The excessive development of the intermetallic compounds directs to have the brittleness of the weld joints. Figure 6 shows the Fe-Al binary phase diagram [24], [25] that is having intermetallics. According to Xiaolin Li et al. [26], at Al-rich in the phase diagram, the complex intermetallic compounds available are $\mathrm{FeAl}, \mathrm{Fe}_{5} \mathrm{Al}_{8}, \mathrm{FeAl}_{2}, \mathrm{Fe}_{2} \mathrm{Al}_{5}, \mathrm{Fe}_{4} \mathrm{Al}_{13}$.

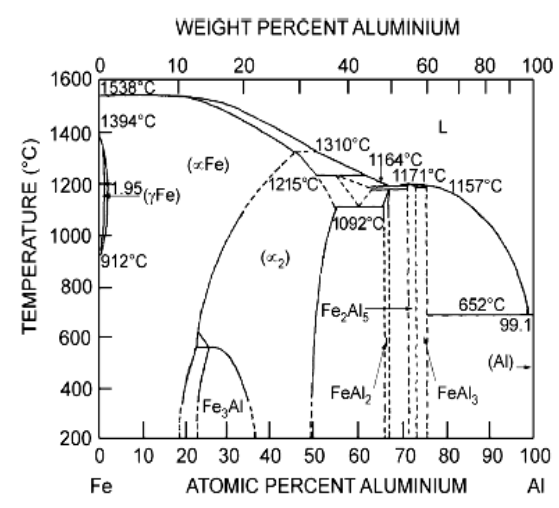

Fig. 6. Aluminium-iron binary diagram [27], [28]

From the literature, the $\mathrm{Fe}-\mathrm{Al}$ intermetallics phases with their structures are $\mathrm{AlFe}(\mathrm{BCC}), \mathrm{AlFe}_{3}$ $\left(\mathrm{DO}_{3}\right), \mathrm{Al}_{2} \mathrm{Fe}$ (Triclinic), $\mathrm{Al}_{5} \mathrm{Fe}_{2}$ (orthorhombic), $\mathrm{Al}_{3} \mathrm{Fe}$ (monoclinic) and $\mathrm{Fe}_{3} \mathrm{Al}$ is more stable. Fe $\mathrm{Fe}_{4} \mathrm{Al}_{13}$ forms at the temperature of $1100^{\circ} \mathrm{C}$, but at $800^{\circ} \mathrm{C}$ it would be narrow. The atoms of aluminium and iron content, temperature decides the formation of different phases. Two compounds especially $\mathrm{FeAl}_{3}$ and AlFe have corrosive resistance and good strength at elevated temperatures. The phase $\mathrm{Fe}_{2} \mathrm{Al}_{5}$ is formed 
by the volume expansion. Usually, $\mathrm{Fe}_{2} \mathrm{Al}_{5}, \mathrm{FeAl}_{3}$ phases are found at the weld interface of Al.-steel friction welded dissimilar joints [29]. While increasing the temperature, the formed $\mathrm{Fe}_{2} \mathrm{Al}_{5}$ phase reacts with the iron content and newly generates FeAl.

\section{CONCLUSIONS}

It is understood that the FW method is quite good for joining dissimilar metals like aluminium with steel. The research on FW with faying surface modifications is limited according to the literature survey. A new kind of research at different welding parameters with axial feed rate and upset time may be tried in the frictional joining with different faying surfaces. The increase in axial penetration rate and upset time might increase the strength of the welded joint. Through the computational, with the help of software, it can be analysed over the friction welded joint interface as the analysis is needed for defence, medical and aerospace applications. In this study, it was noted that when selecting the FW' parameters, the nature of the materials to be joined and the dimensions of the specimens should be considered, otherwise the specimens may get damaged or the weld gets defects. From the experiments and testing results, the faying surface modifications influence the joint property and may increase their strength. The experiment with a hemispherical faying surface (E3) showed a good bonding and maximum tensile strength value compared with others E1, E2. We achieved the limited axial shortening here. It is proved here that exceeding $100 \%$ joint efficiency can be obtained by modifying weld faying surfaces. It is required to eliminate the intermetallics at the WI region to improve ductility and tensile strength of the joint.

\section{REFERENCES}

[1] Liu C., Dong C. L., Internal Residual Stress Measurement on Linear Friction Welding of Titanium Alloy Plates with Contour Method, Trans. Nonferrous Met. Soc. China, 2014, vol. 24, pp. 1387-1392.

[2] Srirangarajalu N., Rajadurai A., Hardness and Tensile Behaviour of Friction Stir Welded Cu-40wt\%Zn Brass, Indian J. of Engineering \& Materials Sciences, 2017, vol. 24, pp. 63-68.

[3] Wang H., Qin G., Geng P., Ma X., Interfacial Microstructures and Mechanical Properties of Friction Welded Al/Steel Dissimilar Joints, Journal of Manufacturing Processes, 2020, vol. 49, pp. 18-25.

[4] Kato K., Tokisue H., Dissimilar Friction Welding of Aluminium Alloys to Other Materials, Welding International, 2004, vol. 18 , iss. 11 , pp. $861-867$.

[5] Manideep D., Balachandar K., Welding ParametersMetallurgical Properties Correlation of Friction Welding of Austenitic Stainless Steel and Ferritic Stainless Steel, Journal of Applied Sciences, 2012, vol. 12, pp. 1013-1019.

[6] Paventhan R., Lakshminarayanan P. R., Balasubramanian V., Optimization of Friction Welding Process Parameters for Joining Carbon Steel and Stainless Steel, J. of Iron and Steel Research International, 2012, vol. 19, iss. 1, pp. 66-71.

[7] Kimura M., Suzuki K, . Kusaka M., Kaizu K., Effect of Friction Welding Condition on Joining Phenomena and Mechanical Properties of Friction Welded Joint between 6063 Aluminium Alloy and AISI 304 Stainless Steel, Journal of Manufacturing Processes, 2017a, vol. 26, pp. 178-187.
[8] Besharati Givi M. K., Asadi P., Advances in Friction-Stir Welding and Processing, Woodhead Publishing Series in Welding and Other Joining Technologies, 2014, pp. 1-19.

[9] Senthil Murugan S., Sathiya P., Noorul Haq A., Experimental study on the effect of silver, nickel and chromium interlayers and upset pressure in joining SS304L-AA6063 alloys through direct drive friction welding process., 2020, J Braz. Soc. Mech. Sci. Eng., vol. 42, iss. 611.

[10] Maalekian M., Friction Welding-Critical Assessment of Literature, Science and Technology of Welding and Joining, 2007, vol.12, pp. 738-759.

[11] Rombaut P., Wim D. W., Koenraad F., Friction welding of Steel to ceramic, Sustainable Construction and Design, Ghent University, Laboratory Soete: Gent, Belgium, vol. 2, no. 3, 2011. [12] Dawood A. B., Butt S. I., Hussain G, Siddiqui M. A., Maqsood A., Zhang F., Thermal Model of Rotary Friction Welding for Similar and Dissimilar Metals, Metals, 2017, vol. 7(6), pp. 224. [13] Kessler M., Saenger S., Haubold M., Zaeh M. F., Modelling of Upset and Torsional Moment during Inertia Friction Welding, J. of Mater. Process. Technol, 2016, vol. 227, pp. 34-40.

[14] Schmicker D., Persson P. O., Strackeljan J., Implicit Geometry Meshing for the Simulation of Rotary Friction Welding, Journal of Comput. Physics 2014, vol. 270, pp. 478-489.

[15] Polami S. M., Reinhardt R., Rethmeier M., Schmid A., Joint-Site Structure Friction Welding Method as a Tool for Drive Pinion Light Weighting in Heavy-Duty Trucks, Journal of Materials Processing Technology, 2014, vol. 214, pp. 1921-1927.

[16] Kumar R., Balasubramanian M., Application of Response Surface Methodology to Optimize Process Parameters in Friction Welding of Ti-6Al-4V and SS304L rods, Trans. Nonferrous Met. Soc. China, 2015, vol. 25, pp. 3625-3633.

[17] Baffari D., Buffa G., Campanella D., Fratini L., Micari F., Friction Based Solid-State Welding Techniques for Transportation Industry Applications, Procedia CIRP, 2014, vol. 18, pp. 162-167.

[18] Baghel P. K., Nagesh. D. S., Mechanical Properties and Microstructural Characterisation of Automated Pulse TIG Welding of Dissimilar Aluminium Alloy, Indian Journal of Engineering \& Materials Sciences, 2018, vol. 25, pp. 147-154.

[19] Lu Y., Sage D. D., Fink C., Zhang W., Dissimilar Metal Joining of Aluminium to Zinc-Coated Steel by Ultrasonic Plus Resistance Spot Welding-Microstructure and Mechanical Properties, Science and Technol. of Welding and Joining, 2020, vol. 25:3, pp. 218-227.

[20] Senthil Murugan S., Noorul Haq A., Sathiya P., A Effect of welding parameters on the microstructure and mechanical properties of the friction-welded dissimilar joints of AA6063 alloy and faying surface-tapered AISI304L alloy, Weld World, 2020, vol. 64, pp. 483-499.

[21] Li W., Vairis A., Ward R. M., Advances in Friction Welding. Advances in Materials Science and Engineering, vol. 2014, article ID 204515, 1 page.

[22] Gullino A., Matteis P., D'Aiuto F., Review of Aluminum-toSteel Welding Technologies for Car-Body Applications. Metals, 2019, vol. 9, p. 315.

[23] Basariya M. I. R., Mukhopadhyay N. K., Structural and Mechanical Behaviour of Al-Fe Intermetallics, Intermetallic Compounds Book, 2018.

[24] Murray J. L., Fe-Al Binary Phase Diagram, Alloy Phase Diagrams, ASM International, Materials Park, USA, 1992, pp. 54.

[25] Sinha H., Corneliusson J., Turba K., Iyengar S., A Study on the Formation of Iron Aluminide (Feal) from Elemental Powders, J. of Alloys and Compounds, 2015, 636, 261-269.

[26] Li X., Scherf A., Heilmaier M., Stein F., The Al-Rich Part of the Fe-Al Phase Diagram, Journal of Phase Equilibria and Diffusion, 2016, vol. 37, pp. 162-173.

[27] Mridha S., Sarker D., Iron aluminide coatings on steel through powder preplacement and surface melting techniques, International Conference on Advances in Materials and Processing Technologies 2008, Kingdom of Bahrain, vol: 2-5, 2008.

[28] Mehta K., A review on friction-based joining of dissimilar aluminum-steel joints, Journal of Materials Research, 2019, vol. 34(1), pp. 78-96.

[29] Suresh D. Meshram, Madhusudhan Reddy G., Friction Welding Of AA6061 To AISI 4340 Using Silver Interlayer, Defence Technology, 2015, vol. 11, pp. 292-298. 